\title{
Intervenção no Rio São Francisco: melhoramento para navegação.
}

\section{$\underline{\text { Ítala Rayane de Castro Machado }}{ }^{1}$; Ivoneide de França Costa ${ }^{2}$; Terceiro}

\section{Autor $^{3}$ e Quarto Autor ${ }^{4}$}

1. Bolsista PIBIC/CNPq, Graduanda em Engenharia Civil, Universidade Estadual de Feira de Santana, email: italacastro03@gmail.com

2. Orientador, Departamento de Letras e Artes, Universidade Estadual de Feira de Santana, e-mail: neidefc@uefs.br

3. Participante do projeto ou núcleo tal, Departamento de Nome, Universidade Estadual de Feira de Santana, e-mail: codinome@ provedor.br

4. Participante do projeto ou núcleo tal, Departamento de Nome, Universidade Estadual de Feira de Santana, e-mail: codinome@ provedor.br

PALAVRAS-CHAVE: navegação; comissão; melhoramento.

\section{INTRODUÇÃO}

Com o intuito de facilitar as transações de mercadorias e pessoas, a ideia do governo era criar nas regiões relacionadas com o vale do Rio São Francisco um amplo sistema geral de transporte utilizando as vias de comunicação fluvial, ferroviária e terrestre, criando assim um grande sistema de comunicação e transporte.

Esse melhoramento foi feito pela Comissão de Melhoramento do Rio São Francisco (CMRSF), que em primeiro instante foi composta por: Antonio Plácido Peixoto do Amarante, engenheiro chefe; Theodoro Fernandes Sampaio, 1ำ engenheiro; Albuquerque F Ramos, condutor; João Emiliano Amarante, engenheiro; Evaristo Galvão Filho, engenheiro auxiliar, Foligonio Magalhães de Souza e Moisés Deschaps de Montmorencey (desenhistas) e Reginaldo Candido da Silva, engenheiro auxiliar. (Costa, 2013, p. 187)

As atividades da CMRSF iniciaram em 1883 com serviços tais como: sondagens, levantamentos de plantas, nivelamento e determinação da velocidade das correntes marítimas, seguida com serviço de desobstrução e da construção de diques. 
Foi feita uma pesquisa bibliográfica sobre a história e meios e métodos usados para a desobstrução do Rio São Francisco, tendo como ponto de partida os trabalhos da CMRSF. Tal pesquisa foi realizada na documentação do Arquivo Nacional do Rio De janeiro (ANRJ) e em outras diversas fontes bibliográficas sobre o tema.

\section{RESULTADOS E/OU DISCUSSÃO (ou Análise e discussão dos resultados)}

Ao decorrer das obras do melhoramento, a CMRSF foi dividida em algumas turmas com diferentes funções, com a intenção de aumentar a velocidade dos trabalhos. A primeira turma, no início do mês de junho de 1883, com a construção da planta topográfica do canal da cachoeira, deste primeiro trecho da desobstrução. Enquanto a segunda turma iniciou com a construção da planta do canal da cachoeira na junção inferior. Enquanto isso o Engenheiro Albuquerque F Ramos deu início nesse período ao nivelamento longitudinal, trabalho urgente e indispensável para a fixação das escalas e trabalhos de sondagens no canal. No fim do mês junho, deu-se começo a planta geral do canal da cachoeira em escala de 1:4000, e continuaram o trabalho de nivelamento, das sondagens e seções transversais.

E enquanto inaptos a praticar trabalhos em campo, a comissão praticava trabalhos de escritório, como construções de plantas, desenhos de curvas meteorológicas, cálculos para conhecer o volume de água que certo molhe faz desviar para algum canal (ANRJ; 1883-1884)

\section{CONSIDERAÇÕES FINAIS (ou Conclusão)}

As informações históricas obtidas mostram que os métodos usados para a desobstrução do rio e melhoramento para navegação, no geral, se destacavam em: Fechamento de saídas laterais para impedir a saída de água do canal específico que for escolhido; construção de molhes com a intenção de desviar um certo volume de agua para o canal que estiver sendo adaptado; formação de rampas e corredeiras, com o propósito de concentrar a agua e 
guiar correntes, de modo separar através de cachoeiras locais e levantar os níveis das aguas de maneira a aumentar a profundidade de diques ou paredões; e na remoção de rochas que obstruem a passagem e no revestimento de alguns pontos, onde a corrente da água for erosão (ANRJ; 1883-1884)

\section{REFERÊNCIAS}

LISBOA, Alfredo. O Exame Feito as Obras do Melhoramento do Alto S. Francisco. Rio de janeiro: Imprensa Nacional, 1889, p. 10;

Arquivo Nacional do Rio De Janeiro (ANRJ); Lembrete Diário da CMRSF referente aos anos de 1883-1884, pasta № 57, diário 57-1, (manuscrito);

ANRJ; Lembrete Diário da CMRSF referente ao ano de 1884, pasta № 57, diário 57-1, (manuscrito);

AMARANTE, Antônio Plácido do. Exposição sobre o melhoramento da parte encachoeirada do rio S. Francisco, entre a cachoeira de Sobradinho e Jatobá 428 quilômetros, março de 1883;

COSTA, Ivoneide de França Costa. Comissão Hidráulica do Império (18791880): profissionalização e técnica a serviço dos melhoramentos no século XIX. Tese (Doutorado em História das Ciências) - Programa de PósGraduação em História das Ciências e das Saúde - COC - Fiocruz, Rio de Janeiro. 2013, p.187. 